\title{
Performance of supersonic steam ejectors considering the nonequilibrium condensation phenomenon for efficient energy utilisation
}

\author{
Yan Yang ${ }^{1}$, Xiaowei Zhu ${ }^{1}$, Yuying Yan ${ }^{2}$, Hongbing Ding ${ }^{3}$, Chuang Wen 1, 2, * \\ ${ }^{1}$ Department of Mechanical Engineering, Technical University of Denmark, Nils \\ Koppels Allé, 2800 Kgs. Lyngby, Denmark \\ ${ }^{2}$ Faculty of Engineering, University of Nottingham, University Park, Nottingham \\ NG7 2RD, UK \\ ${ }^{3}$ Tianjin Key Laboratory of Process Measurement and Control, School of Electrical \\ and Information Engineering, Tianjin University, Tianjin 300072, China \\ *Corresponding author: Chuang Wen, Email: cwen@mek.dtu.dk
}

\begin{abstract}
Supersonic ejectors are of great interest for various industries as they can improve the quality of the low-grade heat source in an eco-friendly and sustainable way. However, the impact of steam condensation on the supersonic ejector performances is not fully understood and is usually neglected by using the dry gas assumptions. The non-equilibrium condensation occurs during the expansion and mixing process and is tightly coupled with the high turbulence, oblique and expansion waves in supersonic flows. In this paper, we develop a wet steam model based on the computational fluid dynamics to understand the intricate feature of the steam condensation in the supersonic ejector. The numerical results show that the dry gas model exaggerates the expansion characteristics of the primary nozzle by $21.95 \%$, which predicts the Mach number of 2.00 at the nozzle exit compared to 1.64 for the wet steam model. The dry gas model computes the static temperature lower to $196 \mathrm{~K}$, whereas the wet steam model predicts
\end{abstract}


the static temperature should above the triple point due to the phase change process. The liquid fraction can reach $7.2 \%$ of the total mass based on the prediction of the wet steam model. The performance analysis indicates that the dry gas model over-estimates a higher entrainment ratio by $11.71 \%$ than the wet steam model for the steam ejector.

Keywords: Steam ejector; condensation; dry gas; wet steam; entrainment ratio

\section{Introduction}

Steam ejectors provide an economic and eco-friendly development to consume the energy resource in a sustainable way [1-3]. The high-pressure steam throughout a primary nozzle inside a supersonic ejector can improve the quality of the low-grade heat energy by entraining the low-pressure steam [4]. Moreover, a supersonic steam ejector shows great advantages including simple structure, easy operation and high reliability [5]. It, therefore, has been used in various industrial processes, such as refrigeration system [6], seawater desalination [7], and solar energy utilization [8], and steam generation system [9]. Strusnik et al. [10] investigated the effect of noncondensable gas on the heat transfer behaviour in a steam turbine condenser and modelling of the steam ejector pump system by controlling the gas extraction rate through extraction tubes. An appropriate cross-section dimension of the Laval nozzle reduced the consumption of the motive steam and improved the efficiency of the steam ejector pump system. Strusnik et al. [11] innovatively used the supervised machine learning modelling to evaluate the energy efficiency of a steam ejector and an electric vacuum pump for a turbine condenser air extraction system. Their study proposed basic guidelines for the selection of an appropriate condenser vacuum pumps system of a 
steam turbine.

The structural design and optimization have been conducted by the experimental investigations on the supersonic steam ejector [12-14]. Dong et al. [15] experimentally investigated the impacts of the operating temperature and nozzle exit position on the steam ejector performance. They observed that the coefficient of performance declined with the decrease of the diameter of the constant area when fixed the nozzle exit position. Ramesh and Sekhar [16] conducted the experimental measurements to investigate the effect of six suction chamber angles on the entrainment ratio of a steam ejector. They found that the increasing suction chamber angle from $0^{\circ}$ to $12^{\circ}$ improves the entrainment ratio and above that the performance decreases significantly. Reddick et al. [17] experimentally studied the steam ejector performance with the secondary fluid of a mixture of steam and $\mathrm{CO}_{2}$. The results showed that the increase in the $\mathrm{CO}_{2}$ amount improved the critical entrainment ratio without changing the critical pressure.

The computational fluid dynamics (CFD) modelling was employed to predict and optimize the working performance of steam ejectors. However, most of the numerical simulation still focused on the single-phase steam flow without considering the condensation phenomenon that happened in supersonic flows. Sriveerakul et al. [18] developed and validate the CFD modelling for steam ejectors by comparing the numerical and experimental results of the static pressure and entrainment ratio. They then employed CFD modelling to investigate the complicated flow phenomenon inside the steam ejector [19]. They presented that the longer throat section increased the critical back pressure while its influence on the entrainment ratio could be ignored in 
steam ejectors. The numerical assessment was performed by Yang et al. [20] to analyze the influence of different nozzle shapes on the mixing process inside the steam ejector including the conical, elliptical, square, rectangular and cross-shaped nozzles. They stated that the entrainment ratios were improved with the design of the cross-shaped and square primary nozzles. Allouche et al. [21] used the single-phase flow and ideal gas law to model the flow structure and mixing process inside the steam ejector involving a spindle located in the entrance of the primary nozzle. It revealed that a reduced recompression thanks to the two shock waves in the diffuser at low condenser pressures influenced the entrainment ratio very slightly. Ariafar et al. [22] neglected the condensation behaviour to numerically predict the influence of the mixing layers on the entrainment ratio in a steam ejector based on the ideal gas law. The computational results showed that the mixing layers impacted the entrainment ratios more significantly at lower secondary pressure. Han et al. [23] employed the ideal gas model to analyse the influence of the boundary layer separation on ejector performance. Their results showed that a large throat diameter or a large nozzle exit position induced the severe phenomenon of the boundary layer separation, which resulted in the decrease of entrainment ratio of the steam ejector. Tang et al. [24] newly designed a steam ejector with an auxiliary entrance and performed the numerical simulation to evaluate the ejector performance based on the ideal gas law. They disclosed that the simultaneously auxiliary entrances located at the throat and diffuser significantly improved the entrainment ratios. Wang et al. [25] predicted the effect of the primary pseudo-shock pattern on the performance of the steam ejector using CFD modelling. The numerical 
results from the ideal gas assumption indicated that the pattern of primary pseudo-shock flow was affected by the critical and sub-critical conditions.

A number of optimizations on the supersonic steam ejector have been performed by the CFD modelling with the assumption of the single-phase flow. Varga et al. [26] carried out the numerical simulation to obtain the effect of geometry size on the entrainment ratio of the steam ejector mainly considering the area ratio between the nozzle and constant area section, nozzle exit position (NXP) and constant area section length. They observed the existence of an optimum area ratio depending on the operating conditions. The NXP influenced both the entrainment ratio and critical back pressure. With the assumption of single-phase flow and ideal gas model, steam ejectors were optimized by $\mathrm{Wu}$ et al. [27] combining the numerical simulation and orthogonal approaches including NXP, the diameters of the nozzle outlet, the mixing section, the diffuser, and the length of the constant area. They found that the outlet diameter of the primary nozzle is the most significant factor to influence the performances of the steam ejector. Ruangtrakoon et al. [28] focused on the influence of the throat and exit sizes of the primary nozzle on the steam ejector performance for a refrigeration cycle. They observed the optimum size of the primary nozzle by analyzing the Mach number contour and entrainment ratio. Fu et al. [29] also employed the ideal gas model to investigate the effect of the primary nozzle on the entrainment ratio of the steam ejector. The numerical results showed that there was an optimal value of the diameter of the nozzle exit to achieve optimum performance. The effect of the mixing section on the entrainment ratio of the steam ejector was obtained by Wu et al. [30] using the CFD 
modelling. They indicated that the vortex appeared in the near wall region at a large converging angle of the mixing part. Tang et al. [31] then used the ideal gas model to numerically optimize the structure of the auxiliary entrance for the steam ejector. They found that the newly designed ejector improved the entrainment ratio by $3.80 \%$ compared to the conventional design. Tang et al. [32] optimized the axial position, width and angle of the auxiliary entrance for the designed steam ejectors using the same CFD modelling. The difference was that the various back pressure was considered in [32] compared to the optimization in [31].

The above mentioned CFD simulations were performed with the assumption that the working fluid followed the single-phase flow and the ideal gas model. However, the fluid flow inside the steam ejector is highly supersonic and reaches low temperature, which induces the nucleation of the steam in the non-equilibrium state. The condensation phenomenon plays an important role in the prediction of the ejector performance, which has been disclosed by the theoretical studies performed by Grazzini et al. [33]. They checked the validity of the assumption of the ideal model in steam ejectors by theoretically comparing the ideal gas law, the spinodal curve, the saturated vapour model, metastable vapour mode and nucleation model. They pointed out that the condensation made a marked difference in supersonic flows at the nozzle exit. Wang et al. [34] investigated the influences of the superheating steam on the flow behaviour inside the primary nozzle and analyzed the condensation parameters in detail including the nucleation rate, droplet numbers, droplet radius and liquid fraction, respectively. It showed that the increasing superheated degree of the steam delayed the onset of the 
condensation and decreased the liquid fraction at the exit of the primary nozzle. In the following study, Wang et al. [35] presented the effects of the area ratio between the nozzle exit and nozzle throat and surface roughness on the condensation process inside the primary nozzle. It showed that the increasing area ratio induced a higher liquid mass fraction and high surface roughness resulted in the sharp increase of entropy generation leading to in more energy wastes. Ariafar et al. [36] compared the effects of the ideal gas and wet steam models on the primary nozzle for steam ejectors. The comparison result indicated that the condensation process improved the mixing between primary and secondary fluids to increase the entrainment ratio. These three simulations in [3436] focused on the condensation in the primary nozzle and ignored the other two important phenomena of the mixing process and shock wave which could be significantly affected by steam condensation.

Only a few studies were performed in steam ejectors involving the nonequilibrium condensation phenomenon. Wang et al. [37] proposed the CFD modelling to predict the condensation phenomenon in the steam ejector based on the commercial code ANSYS FLUENT. It was found that critical back pressure was improved compared to the ideal gas model. Then, they employed the CFD model to solve the effect of the superheated steam on the ejector performance [38]. It was found that the entrainment ratio was improved with the increase of the superheat degree. However, the default wet steam model was less satisfactory to predict the condensation process because their comparison results presented that the CFD model predicted a very earlier Wilson point than experimental data. Ariafar et al. [39] also solved the non-equilibrium 
condensation in a steam ejector using the ANSYS FLUENT. Their numerical results showed that the entrainment ratio and critical back pressure calculated by the wet steam model were $10 \%$ and $7 \%$ higher than that for the ideal gas law, respectively. Sharif et al. [40] developed the condensation model to predict the flow structures inside the supersonic steam ejectors. It showed that the condensation phenomenon induced an extended shock wave position in the ejector's throat and the increase of the entrainment ratio. Mazzelli et al. [41] numerically studied the non-equilibrium condensation in steam ejectors by employing the SST $k$ - $\omega$ turbulence model. They reported that the good agreement was obtained between the numerical and experimental results of the mass flow rates and static pressure profiles in steam ejectors.

In this paper, the wet steam model is developed to predict and evaluate the performance of steam ejectors considering the non-equilibrium condensation phenomenon. The CFD model can capture the complicated interactions among the time scale of steam condensation and complex fluid mixing, as well as shock waves in steam ejectors. The developed numerical model is validated and verified against experimental data of supersonic flows in Laval nozzles and steam ejectors. The wet steam model is further compared to a conventional dry gas assumption to embody the significant role of the condensation process on steam ejector performance. The features of condensation parameters and fluid flow are analysed in details for steam ejectors.

\section{Steam ejector}

A steam ejector usually has five parts: a primary nozzle, a suction chamber, a mixing section, a constant area and a diffuser, as shown in Fig. 1. The converging- 
diverging nozzle was employed as the primary nozzle inside the steam ejector to generate supersonic flow, which entrained the low-pressure steam from the suction chamber. The main dimensions of the steam ejector involved in the CFD simulation were listed in Table 1. The 2D axisymmetric geometry was employed in the CFD modelling to evaluate the performance of the steam ejector. The computational domain was discretized by the structured mesh to reduce the numerical diffusion, as shown in Fig. 2. After the analysis of the mesh independent tests, approximately 63900 cells are employed for the numerical simulation.

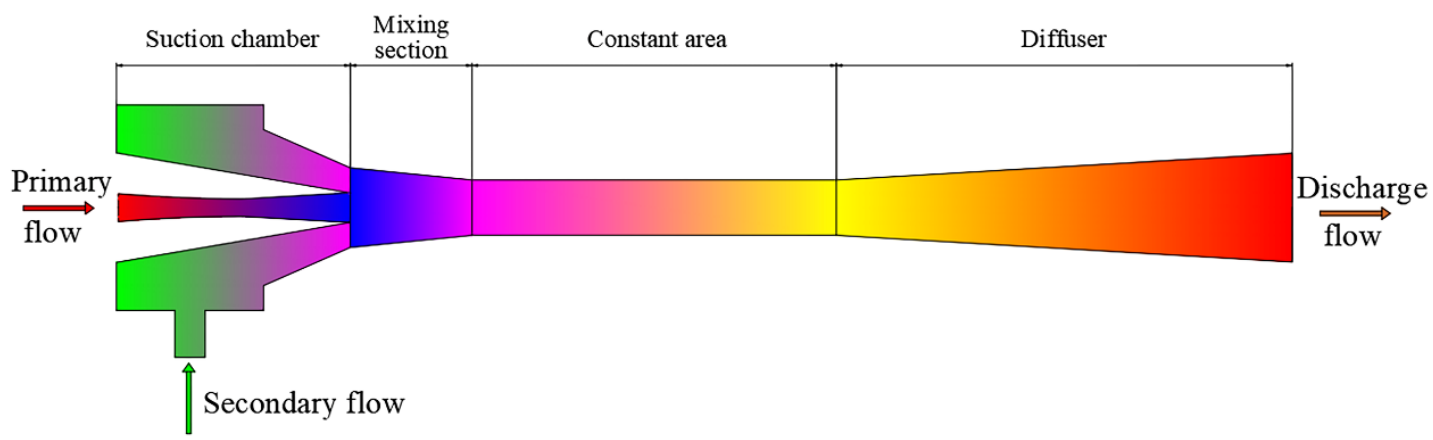

Fig. 1 Schematic diagram of a steam ejector 


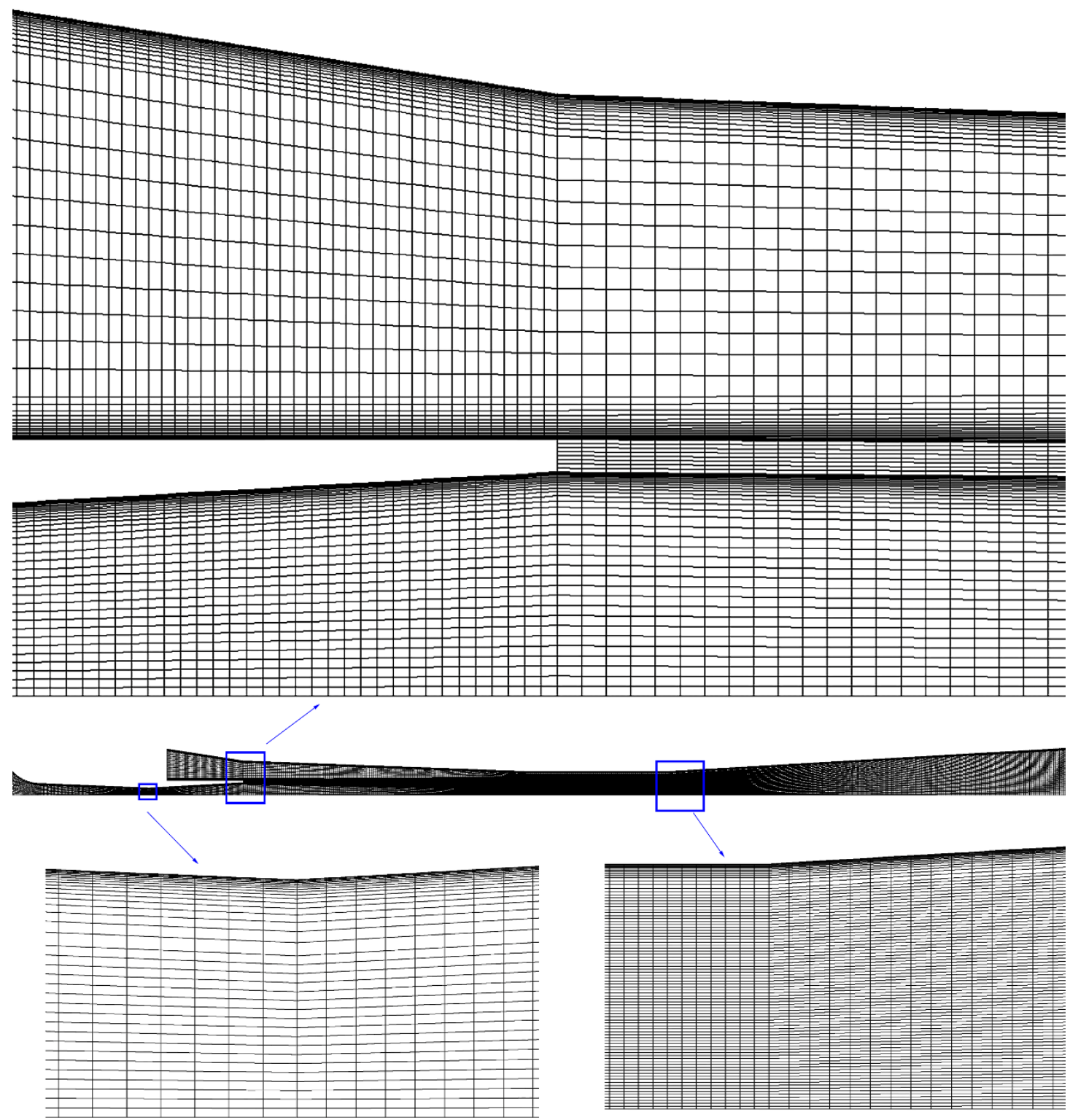

Fig. 2 Grid system of the steam ejector

Table 1. Dimensions of the steam ejector

\begin{tabular}{ll}
\hline Geometrical parameters & Value $(\mathrm{mm})$ \\
\hline Diameter of the primary nozzle inlet & 34.51 \\
Diameter of the primary nozzle throat & 8.00 \\
Diameter of the primary nozzle outlet & 13.60 \\
Converging length of the primary nozzle & 75.06 \\
Diverging length of the primary nozzle & 49.66 \\
Nozzle exit position & 0 \\
Diameter of mixing section inlet & 36.55 \\
Diameter of constant area & 25.40 \\
Diameter of diffuser & 53.69 \\
Length of mixing section & 149.00
\end{tabular}




\section{Numerical model}

The conservation equations of continuity, momentum and energy for the steam

flow are:

$$
\begin{gathered}
\frac{\partial \rho}{\partial t}+\frac{\partial\left(\rho u_{j}\right)}{\partial x_{j}}=-\dot{m} \\
\frac{\partial}{\partial t}\left(\rho u_{i}\right)+\frac{\partial}{\partial x_{j}}\left(\rho u_{j} u_{i}\right)=-\frac{\partial p}{\partial x_{i}}+\frac{\partial \tau_{i j}}{\partial x_{j}}-u \dot{m} \\
\frac{\partial}{\partial t}(\rho E)+\frac{\partial}{\partial x_{j}}\left(u_{j}(\rho E+p)\right)=-\frac{\partial}{\partial x_{j}}\left(\lambda_{e f f} \frac{\partial T}{\partial x_{j}}\right)+\frac{\partial}{\partial x_{j}}\left(u_{i} \tau_{i j}\right)-h \dot{m}
\end{gathered}
$$

where $\rho, u, p$ and $E$ are the density, velocity, pressure and total energy, respectively. $\lambda_{\text {eff }}$ and $T$ are the effective heat conductivity and temperature.

Two transport equations are utilized to describe the phase change process during steam condensation in the supersonic nozzle including the liquid fraction $(y)$ and droplet number $(n)[42]$ :

$$
\begin{aligned}
& \frac{\partial(\rho y)}{\partial t}+\frac{\partial\left(\rho y u_{j}\right)}{\partial x_{j}}=\dot{m} \\
& \frac{\partial(\rho n)}{\partial t}+\frac{\partial\left(\rho n u_{j}\right)}{\partial x_{j}}=\rho J
\end{aligned}
$$

where $\dot{m}$ and $J$ represent the mass generation rate and nucleation rate due to the steam nucleation and condensation, respectively.

$$
\dot{m}=\frac{4 \pi r^{* 3}}{3} \rho_{l} J+4 \pi \rho_{l} n r^{2} \frac{d r}{d t}
$$

where $\rho_{l}$ is the droplet density, $r$ is the droplet radius, $r^{*}$ is the critical radius, $d r / d t$ is the growth rate of droplets. 
The nucleation rate, $J$, employs the classical nucleation theory with the nonisothermal correction of Kantrowitz [43]:

$$
J=\frac{q_{c}}{1+\phi} \frac{\rho_{v}{ }^{2}}{\rho_{l}} \sqrt{\frac{2 \sigma}{\pi m_{v}{ }^{3}}} \exp \left(-\frac{\Delta G^{*}}{k_{B} T_{v}}\right)
$$

where $q_{c}$ is the condensation coefficient, $\phi$ is a correction factor, $m_{v}$ is the mass of a vapour molecule, $k_{B}$ is the Boltzmann's constant. $\Delta G^{*}$ is the Gibbs free energy

The growth rate of droplets, $d r / d t$, in Eq. (6) is calculated by Young's model [4446]:

$$
\frac{d r}{d t}=\frac{\lambda_{v}\left(T_{s}-T_{v}\right)}{\rho_{l} h_{l v} r} \frac{\left(1-r^{*} / r\right)}{\left(\frac{1}{1+2 \beta \mathrm{Kn}}+3.78(1-v) \frac{\mathrm{Kn}}{\mathrm{Pr}}\right)}
$$

where $v$ is the modelling correction coefficient, $\lambda_{v}$ is the heat conductivity coefficient of the vapour, $T_{s}$ is the saturated temperature of the steam, Pr is the Prandtl number, Kn is the Knudsen number.

The ANSYS FLUENT version 18 [47] is employed as the computational platform for this CFD simulation, which is based on the finite volume method. The conservation Eqs. (1) - (3) are directly solved in FLUENT, while the Eqs. (4) - (8) for the liquid phase and the phase change are integrated by the User-Defined-Scalar (UDS) and UserDefined-Function (UDF) interfaces. The shear stress transport (SST) turbulence model [48] is used in this CFD modelling due to the good accuracy to predict the ejector flow and the condensation phenomenon [49]. The pressure inlet conditions are assigned for the primary nozzle entrance and the suction chamber, while the diffuser exit employs the pressure outlet condition. The no-slip and adiabatic walls are assumed for the steam ejector in this simulation. 


\section{Results and discussion}

\subsection{CFD validation}

\subsubsection{Validation for Laval nozzles}

The nozzle B in Moore's experiments [50] is employed to validate the developed wet steam model for supersonic flows. The heights of the entrance, throat and exit of the supersonic nozzle are $112.7 \mathrm{~mm}, 100 \mathrm{~mm}$ and $144 \mathrm{~mm}$, respectively. The structured grid is generated for the computational domain with the refinement mesh in the near wall region. The total pressure and temperature at the nozzle inlet are $25 \mathrm{kPa}$ and 356.7 $\mathrm{K}$, respectively. The flow at nozzle exit is supersonic. Fig. 3 presents the numerical and experimental results of the static pressure and droplet radius inside Moore's nozzle B. The calculated static pressure matches experimental data very well. In particular, the onset of the condensation process is accurately predicted, which occurs approximately at $x=0.11 \mathrm{~m}$. Furthermore, the CFD modelling predicts the droplet radius of $0.053 \mu \mathrm{m}$ at $x=0.37 \mathrm{~m}$, again closing to the $0.050 \mu \mathrm{m}$ measured in the experiment. Therefore, we can conclude that the developed CFD modelling can accurately predict the steam condensation in supersonic flows. 


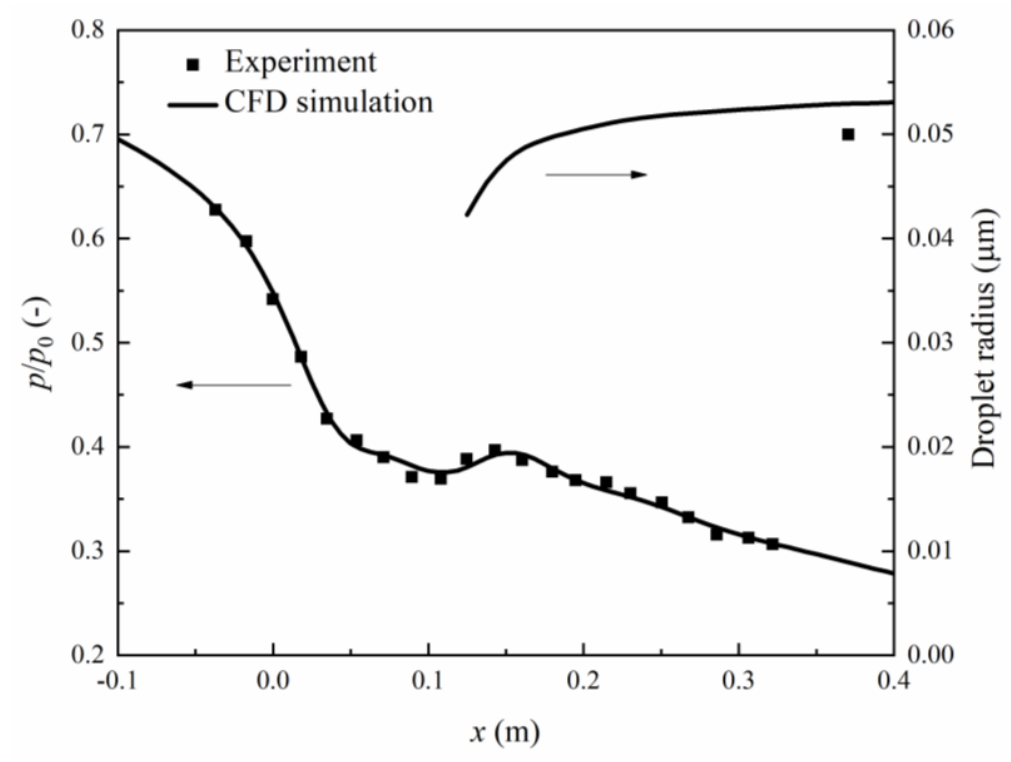

Fig. 3 Numerical and experimental results of static pressure and droplet radius inside Moore's nozzle B.

\subsubsection{Validation for steam ejectors}

In this section, the numerical model is further validated against experimental data of steam ejectors by Al-Doori [51]. The wall pressure was measured in the experiments and therefore, is employed to validate the developed wet steam model for steam ejectors. The operating pressures at primary and suction inlets are $270 \mathrm{kPa}$ and $1.2 \mathrm{kPa}$, respectively. The static pressure at the ejector outlet is of $6 \mathrm{kPa}$. The numerical and experimental results of wall pressure are compared in Fig. 4, showing a good agreement, which demonstrates that the developed CFD model is able to well predict the condensation phenomenon occurring in real supersonic ejectors. 


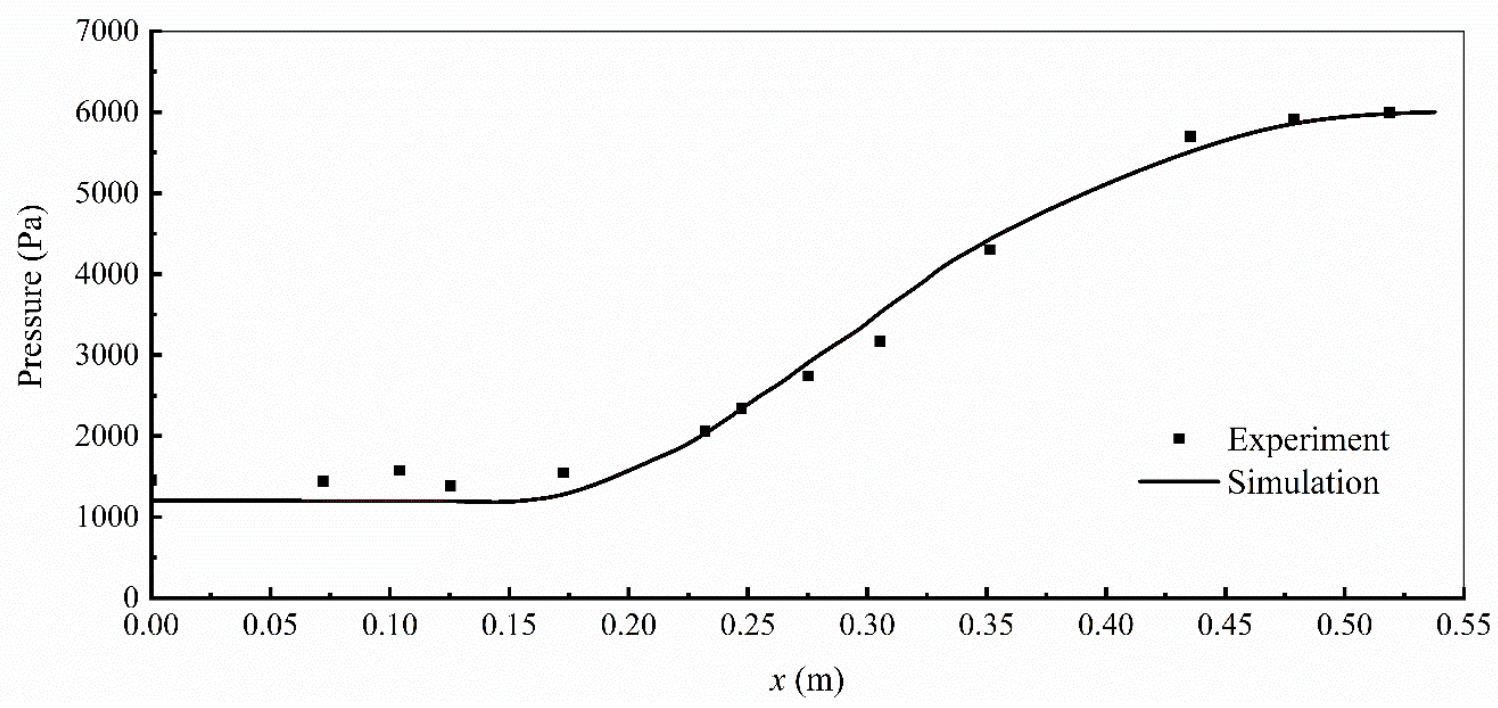

Fig. 4 Numerical and experimental results of wall pressure of a steam ejector

\subsection{Steam expansion and Mach numbers}

In the steam ejector, the high-pressure flow accelerates inside the primary nozzle and reaches the choking state at the nozzle throat, which leads to the further expansion of the steam to supersonic flows. The Mach numbers calculated by the dry gas and wet steam models are both shown in Fig. 5, which explain the expansion and mixing processes in detail. The shock trains appear in the downstream of the exit plane of the primary nozzle both for the dry gas and wet steam flows, and both predict the choked flows at the constant area. The under-expanded wave is created in supersonic flows, which indicates that the static pressure at the exit plane of the primary nozzle is higher than that in the mixing section. This pressure difference induces the occurrence of the diamond wave pattern including the alternant appearances of the oblique shocks and expansion waves inside the mixing chamber and constant area.

Although both models predict similar shock wave patterns, the discrepancy in terms of the local Mach number magnitude is distinctively shown in Fig. 5. At the exit plane of the primary nozzle, the Mach number is approximately 2.00 based on the dry 
gas assumption, whereas it is 1.64 for the wet steam model. This indicates that the dry gas model causes a large error in modelling the flow field in the supersonic ejector. Therefore, the strength of the expansion wave is also overestimated by the dry gas model. The Mach number of the dry gas flow can reach 2.28 at the second expansion wave, while it is only approximately 1.87 for the wet steam flow. It should be noted that the expansion waves significantly influence the steam ejector performance of the entrainment ratio. The presence of the shock trains produces the shear stress layer interfacing between the high-pressure primary flow and the low-pressure secondary flow. The over-expansion due to dry gas assumption means that the dry gas model overestimates the entrainment of secondary fluids into the mixing chamber than the real situation.

The Mach number profile predicted by the wet steam model increases along the primary nozzle, but it appears a decline in the downstream of the nozzle throat due to the phase change process in supersonic flows, while it starts to diverge from the dry gas model. When the fluid flow goes through the mixing chamber, the fluctuation of the Mach number is observed at the central line of the steam ejector both for the dry gas and wet steam models. Although the dry gas and wet steam models predict a similar expansion level of the steam flow at the first under-expansion wave, the wet steam model calculates much lower Mach numbers in the rest part of the mixing section and constant areas compared to the dry gas model. 


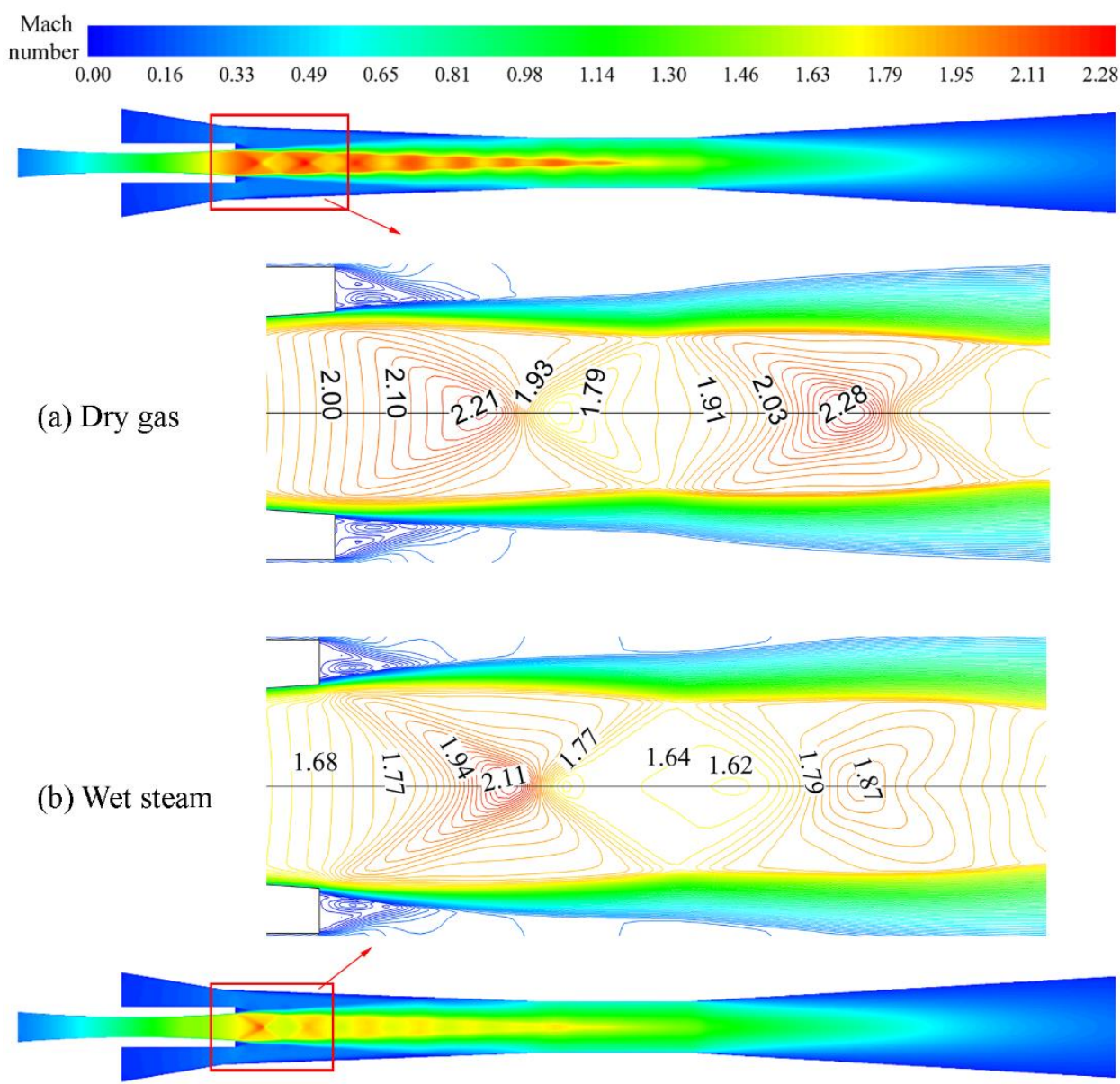

(c) Dry gas + Wet steam

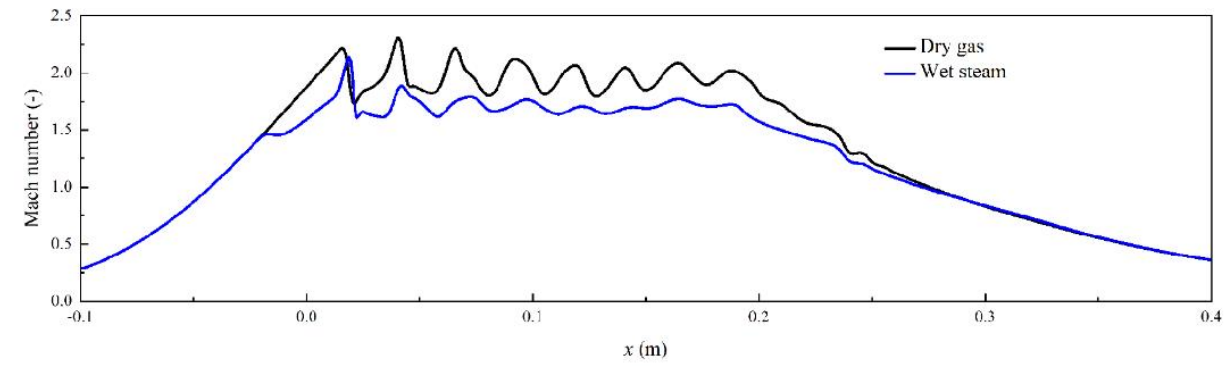

Fig. 5 Mach number inside the steam ejector for dry gas and wet steam flows

\subsection{Static pressure and temperature}

Fig. 6 presents the static pressure calculated by the dry gas and wet steam models, including the pressure contours inside the steam ejector and the pressure profiles at the central line of the ejector. The alternant oblique shocks and expansion waves are observed from the static pressure contours as a consequence of the under-expansion phenomenon in supersonic flows, which are also reflected by the oscillations of the 
static pressure profiles at the central line of the steam ejector. The amplitude of the static pressure fluctuation predicted by the dry gas assumption is stronger than that of the wet steam model. It indicates that a great number of the liquid droplets due to the condensation phenomenon contribute to the heat transfer between the gaseous and liquid phases, which mitigates the jump of the static pressure in the diamond pattern of supersonic flows.

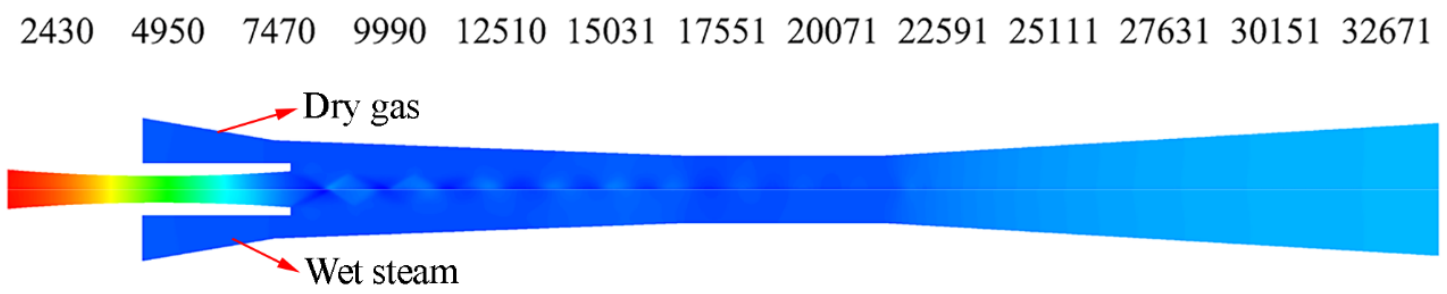

(a) Static pressure contours along the steam ejector

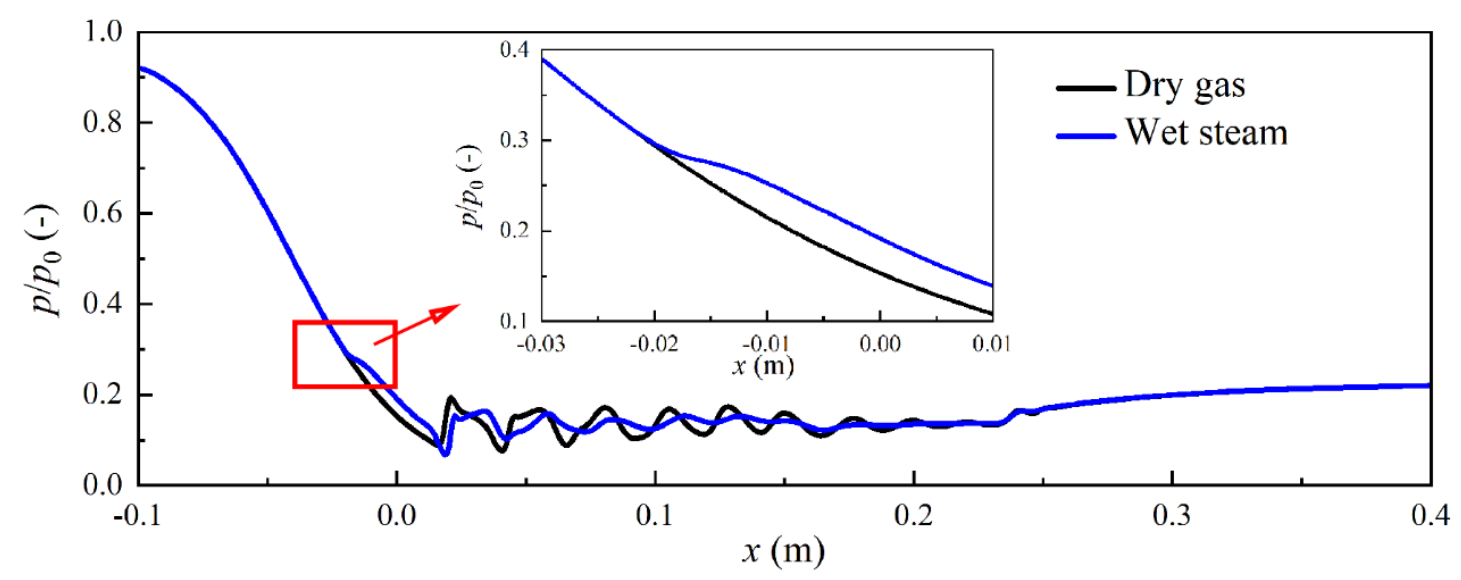

(b) Static pressure profiles at the central line of the steam ejector

Fig. 6 Static pressure along the steam ejector for dry gas and wet steam flows

Fig. 7 shows the static temperature based on the dry gas and wet steam models. The significant differences are observed between the dry gas and wet steam simulations both from the temperature contours and profiles at the central line. Without consideration of the non-equilibrium condensation behaviour, the static temperature reduces to $196 \mathrm{~K}$ according to the ideal gas law. In contrast, the wet steam model, which 
involves the condensing heat and mass transfer in supersonic flows, predicts a jump of the static temperature during its decrease inside the primary nozzle. Due to the latent heat release from the condensed phase, the static temperature of the main flow could remain above the triple point of $273.15 \mathrm{~K}$.

196206216226236246256266276286295305315325335345355365375

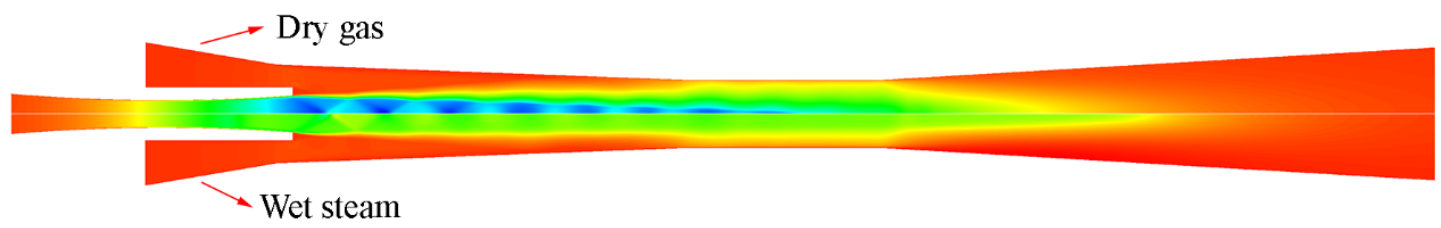

(a) Static temperature contours along the steam ejector

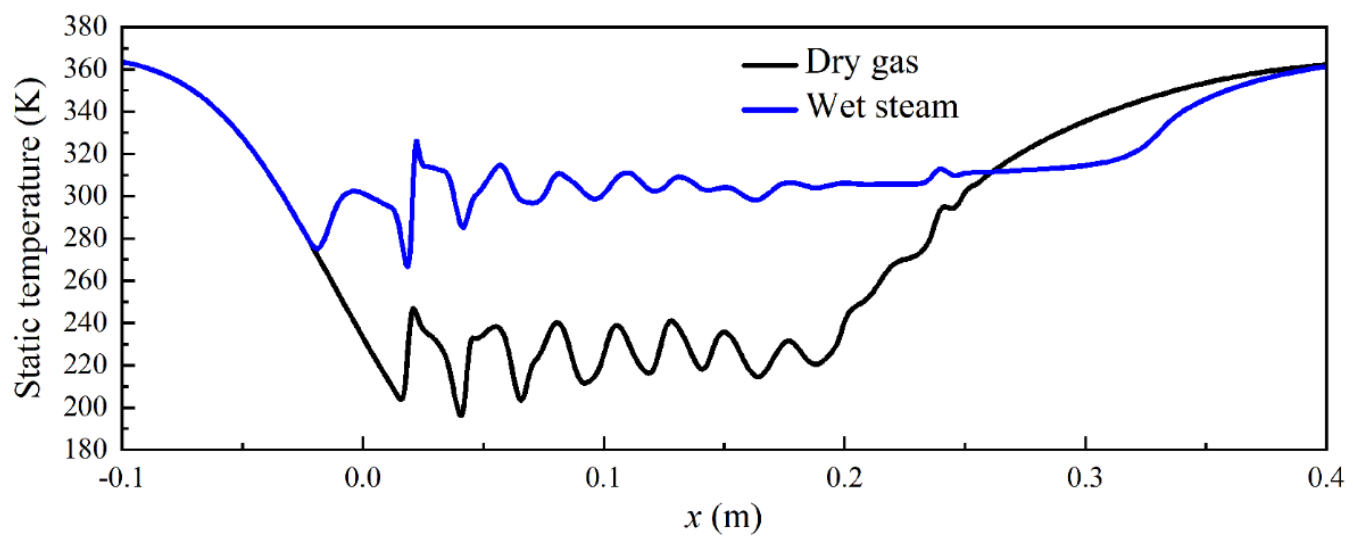

(b) Static temperature profiles at the central line of the steam ejector

Fig. 7 Static temperature along the steam ejector for dry gas and wet steam flows

\subsection{Condensation flow features}

The degree of supersaturation, $S$, is employed to evaluate the thermodynamic state of the vapour within the steam ejector, which is defined as the ratio of the local vapour pressure $\left(p_{v}\right)$ to the equilibrium saturation pressure $\left(p_{s}\right)$ :

$$
S=p_{v} / p_{s}
$$

Fig. 8 shows the contour and profile of degree of supersaturation within the steam ejector, while the contour of the nucleation rate in the steam ejector and the nucleation rate profile at the central line are shown in Fig. 9, respectively. At the early entrance, 
the vapour gradually reaches the equilibrium saturation state at $S=1$, where the nucleation or condensation does not take place immediately due to the zero nucleation rate. It indicates that the equilibrium saturation state of the vapour does not satisfy the nucleation requirement in supersonic flows. Subsequently, the vapour expands in the primary nozzle and the non-equilibrium state is achieved in supersonic flows. The degree of supersaturation goes up to approximately 14.7 in this case, which means that the supercooled vapour is extremely unstable, which results in an explosive nucleation process with the nucleation rate of up to $1.65 * 10^{23} \mathrm{~m}^{-3} \mathrm{~s}^{-1}$. During this process, extensive heat and mass transfer occur between the vapour and liquid phases, which retrieves the vapour towards the quasi-equilibrium state. The fluctuation of the degree of supersaturation is observed in the mixing section and constant area of the steam ejector due to the diamond wave pattern. The vapour will be superheated again when the shock wave occurs in the diffuser, while the degree of supersaturation gradually reduces as the flow proceeds downstream.

The contours and profiles of the droplet radius and liquid fraction inside the steam ejector are described in Fig. 10 and Fig. 11, respectively. When a nucleus is beyond the critical size, it will survive and vapour molecules will continue to condense on the surface of the nucleus, which leads to the growth of the condensed droplets. The mean diameter of the condensed droplets is approximately $15 \mathrm{~nm}$ in this simulation. When the shock wave occurs, the diameter of the droplet is zero. It indicates that the superheated vapour in the downstream of the shock wave results in the re-evaporation of the condensed droplets. 
The aggregation of the condensed droplets forms the liquid fraction, therefore, the contour and profile of the liquid fraction follow with the droplet radius. For this simulation, the maximum liquid fraction is about 0.072 . The liquid fraction decreases to zero in the downstream of the shock wave in the diffuser, which also demonstrates that the condensed liquid re-evaporates to the vapour phase due to the superheated state.
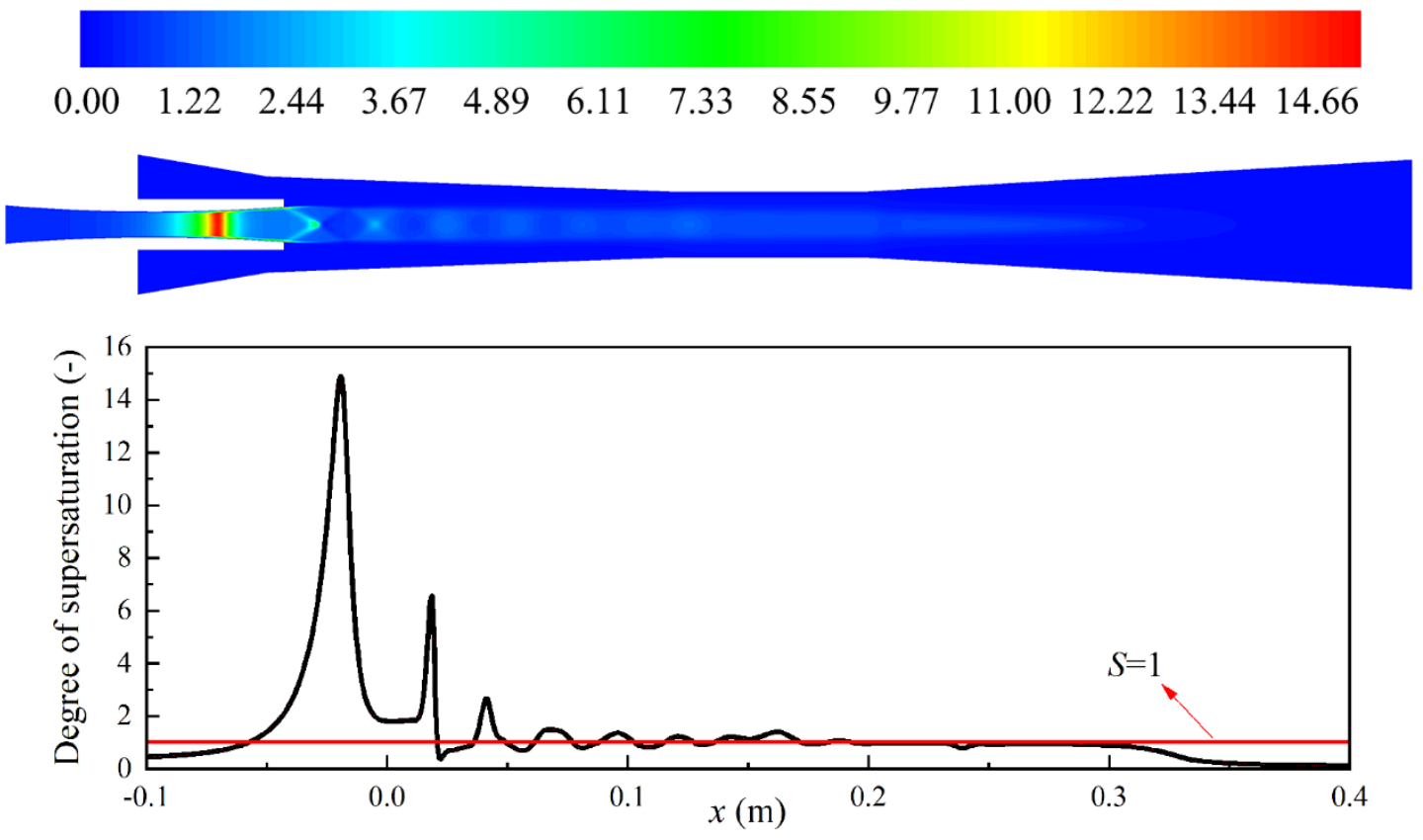

Degree of supersaturation

Fig. 8 Degree of supersaturation along the steam ejector 

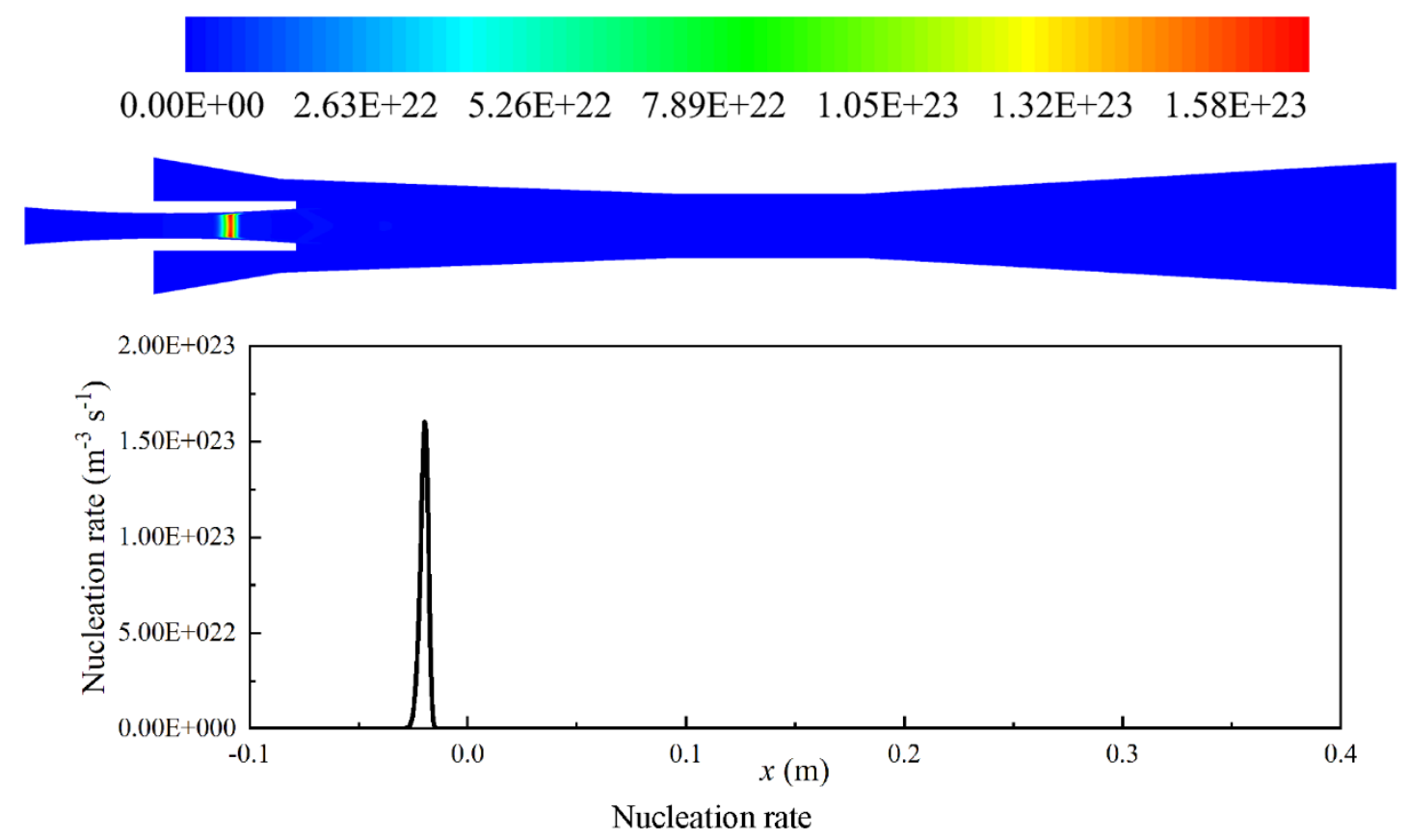

Fig. 9 Nucleation rate along the steam ejector
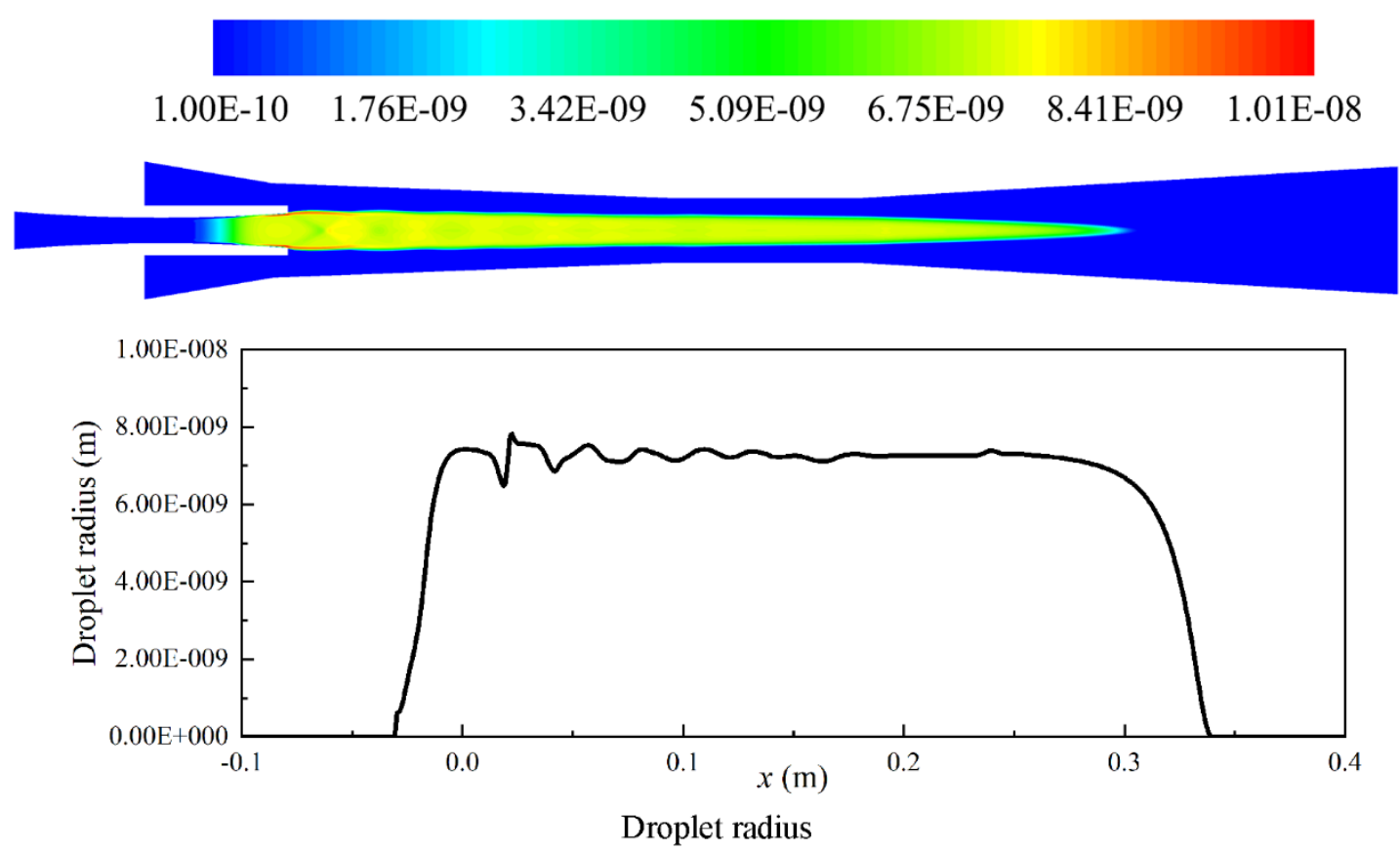

Fig. 10 Droplet radius along the steam ejector 

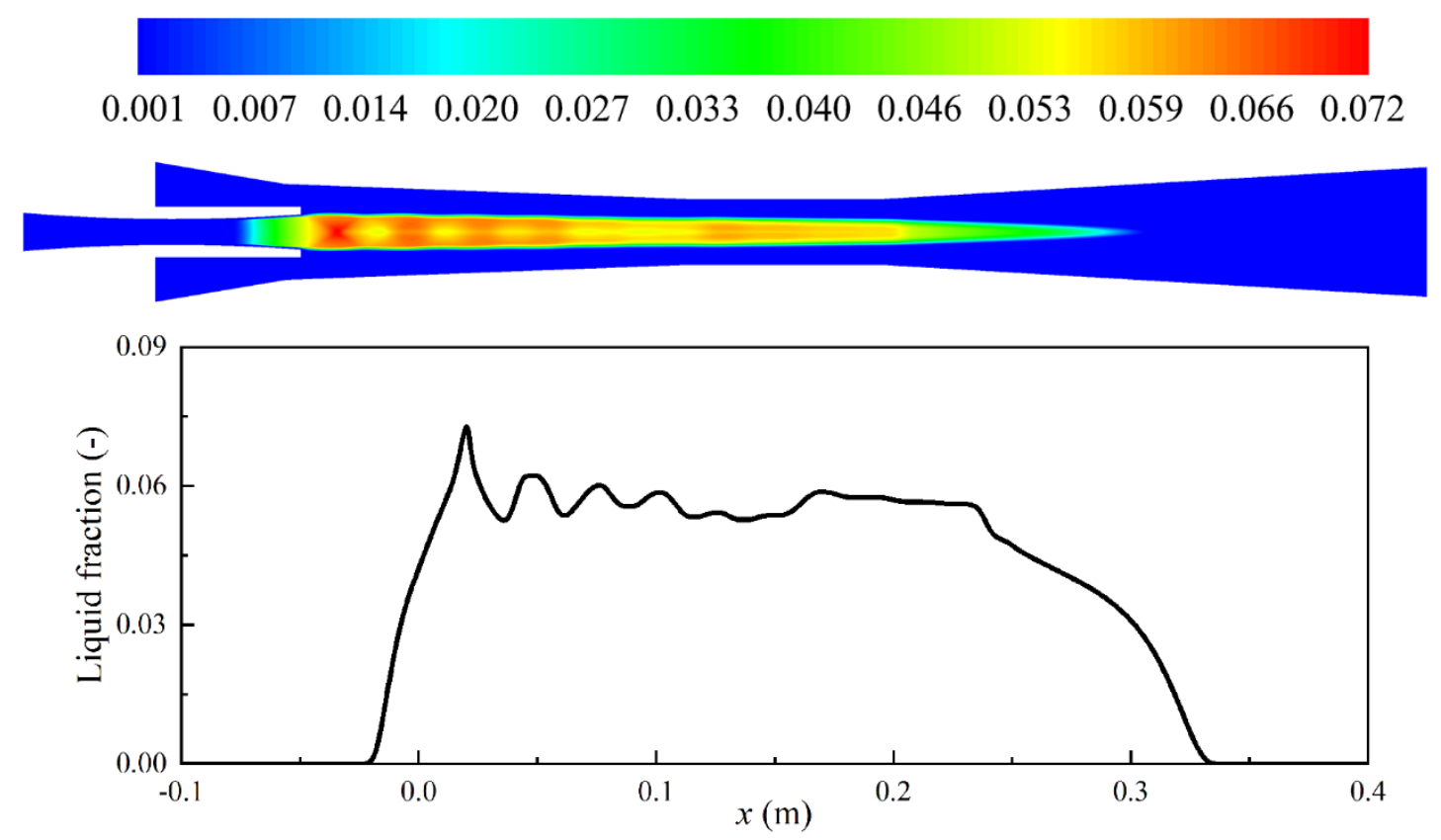

Liquid fraction

Fig. 11 Liquid fraction along the steam ejector

\subsection{Steam ejector performance}

In this section, both the dry gas assumption and the wet steam model are employed to evaluate the performance of the steam ejector, which is expected to see the differences between these two models. One of the popular parameters to represent the ejector performance is the entrainment ratio, which is defined as the ratio of the entrained mass flow from the suction chamber to the motive mass flow from the primary nozzle:

$$
\eta=\frac{m_{s}}{m_{p}}
$$

where $\eta$ is the entrainment ratio, $m_{s}$ is the mass flow from the suction chamber, $m_{p}$ is the mass flow from the primary nozzle.

The mass flow rates of the motivate inlet, suction inlet and ejector outlet are presented in Table 2, predicted by the dry gas assumption and wet steam model. It can 
be seen that the dry gas assumption entrains more fluids from the suction chamber although it predicts less mass flow from the primary nozzle compared to the wet steam model. This can be explained that the dry gas assumption predicts much higher expansion characteristics of lower pressure and temperature than that of the wet steam model in the downstream of the exit plane of the primary nozzle. Correspondingly, the entrainment ratio predicted by the dry gas assumption is higher than that of the wet steam model. The computation error reaches $11.71 \%$ without considering the condensation process inside the steam ejector.

It should be noted that our conclusion on the entrainment ratio calculated by the dry gas assumption and wet steam model is exactly the opposite of the previous results reported by Wang et al. [37], [38] and Sharif et al. [40]. The reason is that the flow structures in the downstream of the exit plane of the primary nozzle are over-expansion in their cases. On the contrary, we focus on the under-expansion flow behaviour as discussed in Section 4.2 and Section 4.3. This also demonstrates that the condensation phenomenon should be involved in the CFD simulation for the steam ejector both under the under-expansion and over-expansion conditions.

Table 2. Mass flow rates and entrainment ratio for the steam ejector

\begin{tabular}{llllll}
\hline Models & Primary & Suction & Discharge & Error of inlet & Entrainment \\
& flow $(\mathrm{kg} / \mathrm{s})$ & flow $(\mathrm{kg} / \mathrm{s})$ & flow $(\mathrm{kg} / \mathrm{s})$ & and outlet & ratio (-) \\
& & & & flow $(\%)$ & \\
\hline Dry gas & 0.004097 & 0.002857 & 0.007093 & -0.020 & 0.6973 \\
Wet steam & 0.004252 & 0.002654 & 0.006903 & 0.043 & 0.6242 \\
\hline
\end{tabular}




\subsection{Discussion}

The wet steam model, which integrates the nucleation model and droplet growth model, is developed to assess the performance of a steam ejector. Complicated interactions involved in this simulation include supersonic flows, expansion waves, non-equilibrium condensation, shock waves, and heat and mass transfer during the phase changes inside the steam ejector. The developed wet steam model shows advantages over the conventional dry gas model in predicting the flow structures and entrainment ratios for supersonic ejectors.

Yang et al. [20] numerically investigated the mixing process in a steam ejector with circle, cross-shaped, square, rectangular and elliptical primary nozzles. The results of the ideal gas model show that the Standard, RNG and Realizable $k-\varepsilon$ models predicted lower critical back pressures. Han et al. [23] evaluated the separation of the boundary layer on the pumping performance of a steam ejector based on the assumption of the dry gas model. The CFD predictions of the entrainment ratio were smaller than the experimental data under all the operating temperatures. Tang et al. [24] proposed a newly designed steam ejector with auxiliary entrainment and evaluated the performance using CFD modelling based on the ideal gas law. Their results showed that the ideal gas model predicted a lower critical back pressure. These studies indicate that the ideal gas model could not well tackle the critical back pressure and entrainment ratios of a steam ejector. By involving the non-equilibrium condensation, the wet steam model provides an efficient approach to evaluate the performance of the steam ejectors.

Furthermore, the development and validation of the wet steam model are 
challenging for steam condensation in supersonic flows. Two cases of nozzle flows are usually employed to validate the wet steam model, which were carried out by Moore et al. [50], Moses and Stein [52]. In Moses and Stein [52] experiments, the static pressure and the liquid fraction were measured in the supersonic nozzle. Dykas and Wroblewski [53], Pillai and Prasad [54], Mirhoseini and Boroomand [55] employed the experimental data of Moses and Stein [52] to validate their wet steam model. Moore et al. [50] measured both the distributions of the static pressure and droplet dimension in their experiments. Although only one droplet size was obtained, it is by far the most relevant data for the validation of the wet steam model, which has been widely used in the studies of Sharif et al. [40], Wang et al. [34], Ahmadpour et al. [56], and Ding et al. [57]. Therefore, by using these two sets of data as the benchmarks, the present wet steam model has been verified to be trusty and better than others in tackle the supersonic flow with phase changes in a real supersonic ejector.

\section{Conclusions}

A wet steam based computational fluid dynamics model is developed to evaluate the performance of the steam ejector taking the condensation phenomenon into account. The heat and mass transfers associated with the vapour condensation are formulated as sources terms, injected into the energy and momentum equations, respectively. The comparisons between the dry gas approach and the developed wet steam model show that the dry gas approach, without considering the condensation, dramatically overestimates the expansion performance of supersonic flows inside the steam ejector. The maximum Mach number predicted by the dry gas approach is approximately $21.95 \%$ 
higher than that of the wet steam model. Due to the ideal gas law being used for the dry gas model, the expansion of the flow results in an unrealistic static temperature field. In contrast, the wet steam model accounts the released latent heat from the condensed fluid, which suggests that the static temperature remains above the triple point inside the supersonic ejector.

The condensation flow predicted by the wet steam model shows that the nonequilibrium steam can acquire a high degree of supersaturation in the primary nozzle, which induces the explosive nucleation and condensation process. The liquid fraction reaches $7.2 \%$ of the total mass for the present study. The disappearance of the liquid fraction and droplet radius indicates that the evaporation occurs in the diffuser of the steam ejector. The numerical results also suggest that the neglect of the condensation phenomenon causes $11.71 \%$ over-prediction of the entrainment ratio. Overall, we conclude that the phase change in steam supersonic ejector should be considered in the numerical models in order to correctly predict the thermal and hydraulic performance.

\section{Acknowledgements}

This project has received funding from the European Union's Horizon 2020 research and innovation programme under the Marie Sklodowska-Curie grant agreement No 792876 and No 778104.

\section{References}

[1] Allouche Y, Varga S, Bouden C, Oliveira AC. Dynamic simulation of an integrated solar-driven ejector based air conditioning system with PCM cold storage. Applied energy. 2017;190:600-11. 
[2] Jeon Y, Jung J, Kim D, Kim S, Kim Y. Effects of ejector geometries on performance of ejector-expansion R410A air conditioner considering cooling seasonal performance factor. Applied Energy. 2017;205:761-8.

[3] Sadeghi M, Yari M, Mahmoudi S, Jafari M. Thermodynamic analysis and optimization of a novel combined power and ejector refrigeration cycleDesalination system. Applied Energy. 2017;208:239-51.

[4] Varga S, Oliveira AC, Diaconu B. Numerical assessment of steam ejector efficiencies using CFD. International Journal of Refrigeration. 2009;32:1203-11.

[5] Chen W, Shi C, Zhang S, Chen H, Chong D, Yan J. Theoretical analysis of ejector refrigeration system performance under overall modes. Applied Energy. 2017; 185:2074-84.

[6] Ruangtrakoon N, Aphornratana S. Development and performance of steam ejector refrigeration system operated in real application in Thailand. International Journal of Refrigeration. 2014;48:142-52.

[7] Tang Y, Liu Z, Shi C, Li Y. A novel steam ejector with pressure regulation to optimize the entrained flow passage for performance improvement in MED-TVC desalination system. Energy. 2018.

[8] Pollerberg C, Ali AHH, Dötsch C. Experimental study on the performance of a solar driven steam jet ejector chiller. Energy Conversion and Management. 2008;49:3318-25.

[9] Damiani L, Revetria R. New steam generation system for lead-cooled fast reactors, based on steam re-circulation through ejector. Applied Energy. 2015;137:292-300. 
[10] Strušnik D, Golob M, Avsec J. Effect of non-condensable gas on heat transfer in steam turbine condenser and modelling of ejector pump system by controlling the gas extraction rate through extraction tubes. Energy Conversion and Management. 2016;126:228-46.

[11] Strušnik D, Marčič M, Golob M, Hribernik A, Živić M, Avsec J. Energy efficiency analysis of steam ejector and electric vacuum pump for a turbine condenser air extraction system based on supervised machine learning modelling. Applied energy. 2016;173:386-405.

[12] Varga S, Oliveira AC, Ma X, Omer SA, Zhang W, Riffat SB. Experimental and numerical analysis of a variable area ratio steam ejector. international journal of refrigeration. 2011;34:1668-75.

[13] Sharifi N, Sharifi M. Reducing energy consumption of a steam ejector through experimental optimization of the nozzle geometry. Energy. 2014;66:860-7.

[14] Chandra VV, Ahmed MR. Experimental and computational studies on a steam jet refrigeration system with constant area and variable area ejectors. Energy Conversion and Management. 2014;79:377-86.

[15] Dong J, Chen X, Wang W, Kang C, Ma H. An experimental investigation of steam ejector refrigeration system powered by extra low temperature heat source. International Communications in Heat and Mass Transfer. 2017;81:250-6.

[16] Ramesh A, Sekhar SJ. Experimental studies on the effect of suction chamber angle on the entrainment of passive fluid in a steam ejector. Journal of Fluids Engineering. 2018;140:011106. 
[17] Reddick C, Sorin M, Sapoundjiev H, Aidoun Z. Effect of a mixture of carbon dioxide and steam on ejector performance: An experimental parametric investigation. Experimental Thermal and Fluid Science. 2018;92:353-65.

[18] Sriveerakul T, Aphornratana S, Chunnanond K. Performance prediction of steam ejector using computational fluid dynamics: Part 1. Validation of the CFD results. International Journal of Thermal Sciences. 2007;46:812-22.

[19] Sriveerakul T, Aphornratana S, Chunnanond K. Performance prediction of steam ejector using computational fluid dynamics: Part 2. Flow structure of a steam ejector influenced by operating pressures and geometries. International Journal of Thermal Sciences. 2007;46:823-33.

[20] Yang X, Long X, Yao X. Numerical investigation on the mixing process in a steam ejector with different nozzle structures. International Journal of Thermal Sciences. 2012;56:95-106.

[21] Allouche Y, Bouden C, Varga S. A CFD analysis of the flow structure inside a steam ejector to identify the suitable experimental operating conditions for a solardriven refrigeration system. international journal of refrigeration. 2014;39:186-95.

[22] Ariafar K, Buttsworth D, Al-Doori G, Sharifi N. Mixing layer effects on the entrainment ratio in steam ejectors through ideal gas computational simulations. Energy. 2016;95:380-92.

[23] Han Y, Wang X, Sun H, Zhang G, Guo L, Tu J. CFD simulation on the boundary layer separation in the steam ejector and its influence on the pumping performance. Energy. 2019;167:469-83. 
[24] Tang Y, Li Y, Liu Z, Wu H, Fu W. A novel steam ejector with auxiliary entrainment for energy conservation and performance optimization. Energy Conversion and Management. 2017;148:210-21.

[25] Wang X, Dong J, Zhang G, Fu Q, Li H, Han Y, et al. The primary pseudo-shock pattern of steam ejector and its influence on pumping efficiency based on CFD approach. Energy. 2019;167:224-34.

[26] Varga S, Oliveira AC, Diaconu B. Influence of geometrical factors on steam ejector performance-a numerical assessment. International journal of refrigeration. 2009;32:1694-701.

[27] Wu Y, Zhao H, Zhang C, Wang L, Han J. Optimization analysis of structure parameters of steam ejector based on CFD and orthogonal test. Energy. 2018;151:79-93.

[28] Ruangtrakoon N, Thongtip T, Aphornratana S, Sriveerakul T. CFD simulation on the effect of primary nozzle geometries for a steam ejector in refrigeration cycle. International Journal of Thermal Sciences. 2013;63:133-45.

[29] Fu W, Li Y, Liu Z, Wu H, Wu T. Numerical study for the influences of primary nozzle on steam ejector performance. Applied Thermal Engineering. 2016;106:1148-56.

[30] Wu H, Liu Z, Han B, Li Y. Numerical investigation of the influences of mixing chamber geometries on steam ejector performance. Desalination. 2014;353:15-20.

[31] Tang Y, Liu Z, Li Y, Shi C, Wu H. Performance improvement of steam ejectors under designed parameters with auxiliary entrainment and structure optimization 
for high energy efficiency. Energy Conversion and Management. 2017;153:12-21.

[32] Tang Y, Liu Z, Li Y, Shi C. Combined auxiliary entrainment and structure optimization for performance improvement of steam ejector with consideration of back pressure variation. Energy Conversion and Management. 2018;166:163-73.

[33] Grazzini G, Milazzo A, Piazzini S. Prediction of condensation in steam ejector for a refrigeration system. International Journal of Refrigeration. 2011;34:1641-8.

[34] Wang C, Wang L, Zhao H, Du Z, Ding Z. Effects of superheated steam on nonequilibrium condensation in ejector primary nozzle. International Journal of Refrigeration. 2016;67:214-26.

[35] Wang C, Wang L, Zou T, Zhang H. Influences of area ratio and surface roughness on homogeneous condensation in ejector primary nozzle. Energy Conversion and Management. 2017;149:168-74.

[36] Ariafar K, Buttsworth D, Sharifi N, Malpress R. Ejector primary nozzle steam condensation: Area ratio effects and mixing layer development. Applied Thermal Engineering. 2014;71:519-27.

[37] Wang X-D, Lei H-J, Dong J-L, Tu J-y. The spontaneously condensing phenomena in a steam-jet pump and its influence on the numerical simulation accuracy. International Journal of Heat and Mass Transfer. 2012;55:4682-7.

[38] Wang X, Dong J, Li A, Lei H, Tu J. Numerical study of primary steam superheating effects on steam ejector flow and its pumping performance. Energy. 2014;78:20511.

[39] Ariafar K, Buttsworth D, Al-Doori G, Malpress R. Effect of mixing on the 
performance of wet steam ejectors. Energy. 2015;93:2030-41.

[40] Sharifi N, Boroomand M, Sharifi M. Numerical assessment of steam nucleation on thermodynamic performance of steam ejectors. Applied Thermal Engineering. 2013;52:449-59.

[41] Mazzelli F, Giacomelli F, Milazzo A. CFD modeling of condensing steam ejectors: Comparison with an experimental test-case. International Journal of Thermal Sciences. 2018;127:7-18.

[42] Yang Y, Walther JH, Yan Y, Wen C. CFD modeling of condensation process of water vapor in supersonic flows. Applied Thermal Engineering. 2017;115:135762.

[43] Kantrowitz A. Nucleation in very rapid vapor expansions. The Journal of chemical physics. 1951;19:1097-100.

[44] Young J. The spontaneous condensation of steam in supersonic nozzle. Physico Chemical Hydrodynamics. 1982;3:57-82.

[45] Young J. The condensation and evaporation of liquid droplets at arbitrary Knudsen number in the presence of an inert gas. International journal of heat and mass transfer. 1993;36:2941-56.

[46] Young J. The condensation and evaporation of liquid droplets in a pure vapour at arbitrary Knudsen number. International journal of heat and mass transfer. 1991;34:1649-61.

[47] Fluent A. 18.0 ANSYS Fluent Theory Guide 18.0. Ansys Inc. 2017.

[48] Menter FR. Two-equation eddy-viscosity turbulence models for engineering 
applications. AIAA journal. 1994;32:1598-605.

[49] Wen C, Karvounis N, Walther JH, Yan Y, Feng Y, Yang Y. An efficient approach to separate CO2 using supersonic flows for carbon capture and storage. Applied Energy. 2019;238:311-9.

[50] Moore MJ, Walters PT, Crane RI, Davidson BJ. Predicting the Fog-drop Size in Wet-Steam Turbines. Proc of IMECHE Conf Wet Steam 4, Coventry, UK. 1973.

[51] Al-Doori GFL. Investigation of refrigeration system steam ejector performance through experiments and computational simulations [Ph.D. Thesis]: University of Southern Queensland; 2013.

[52] Moses CA, Stein GD. On the growth of steam droplets formed in a Laval nozzle using both static pressure and light scattering measurements. Journal of Fluids Engineering. 1978;100:311-22.

[53] Dykas S, Wróblewski W. Numerical modelling of steam condensing flow in low and high-pressure nozzles. International Journal of Heat and Mass Transfer. 2012;55:6191-9.

[54] Pillai A, Prasad BVSSS. Effect of wall surface roughness on condensation shock. International Journal of Thermal Sciences. 2018;132:435-45.

[55] Mirhoseini MS, Boroomand M. Multi-objective optimization of hot steam injection variables to control wetness parameters of steam flow within nozzles. Energy. 2017;141:1027-37.

[56] Ahmadpour A, Noori Rahim Abadi SMA, Meyer JP. On the performance enhancement of thermo-compressor and steam turbine blade cascade in the 
presence of spontaneous nucleation. Energy. 2017;119:675-93.

[57] Ding H, Wang C, Wang G. Self-excited oscillation of non-equilibrium condensation in critical flow nozzle. Applied Thermal Engineering. 2017;122:51527. 